\title{
Strategies of Trademark Translation from English into Chinese
}

\author{
Lijun Yang \\ School of Business and Trade \\ Huanghe S\&T University \\ Zhengzhou, China \\ e-mail: 379630960@qq.com
}

\begin{abstract}
Trademark is one of the important ingredients of the product, the major signal of products are distinguished by the consumers and intangible asset of enterprises, which owns the function of value and value's increasing. Trademark translation from one language to another need not only retain elites of mother tongue, but also meet the psychological demand of the consumers. Good trademark translation can bring big fortune to enterprises; but inappropriate trademark will bring a large number of losses to them, so both the name of trademark and the translation should be considered carefully. This article analyzes systematically a lot of representative trademarks, summarizes the strategies of English trademark translation from the following aspects: transliteration, free translation, combination of transliteration and free translation, other strategies of translation, then according to strategies puts forward attention items as follows: simplicity, appropriate words, materialization of products features and relevance.
\end{abstract}

Keywords—English trademark, translation, strategy

\section{INTRODUCTION}

The trademark is a hard core of the merchandise culture and condensation of remarkable characteristics. It is an outcome of economic development and a notable mark which are used by the manufacturers and the dealers to differentiate their products from others'. In the world market, trademarks have become symbols of the enterprises and bridges of direct dialogue between the producers and the consumers, and they are favorable weapons of enterprises entering into the international competition. Good trademarks can arouse the passions of purchase and contain plentiful connotation and distinguishing features of the products. So good trademarks should be attractive and easy to be remembered, read and understood as well. ${ }^{[1]}$

Along with the acceleration of globalization, there is more competition among enterprises. The brand has become the uppermost mode of competition. The trademark is the brand registered legally, and its translation plays very important roles in selling the goods in the world market. The translation of trademark is a cross cultural communication activity. Influence of trademark translation refers to trademark itself, factors of different languages, cultures and abilities of national aesthetic appreciation [2]. How can the trademark translation build up good impression and retain the original culture? This article believes we may adopt the following measures: transliteration, free translation, combination of transliteration and free translation to translate the trademark from English to Chinese in order to improve sales.

\section{STRATEGIES OF TRADEMARK TRANSLATION}

\section{A. Transliteration}

The transliteration refers to Chinese translation of trademarks which have similar pronunciation to the original trademarks on the understanding that the conformity of language is not deviated without missing association or misunderstanding. The transliteration can not be neglected. The kind of translation shows exoticism and improves the attraction of products. The transliteration can be classified into homophonic transliteration, transliteration of short syllable and pure transliteration.

1) Homophonic transliteration. It considers more pronunciation of trademarks and changes some words on the base of pure transliteration occasionally. The pronunciation of these words changed is similar to the original, and it combines with characteristics of the products. Such as: in honor of the Willian Edward Boeing who was the founder of airline company, people confirm the trademark as Boeing which had been translated as Chinese “博音” before, but as the trademark, the translator has changed it into the homophonic Chinese “波 音", the latter can inspire Chinese with numerous infinite imagination to supersonic aircraft.

2) Transliteration of short syllable. The transliteration of short syllable considers more Chinese aesthetic habits, the trademark with two syllables and three syllables can make Chinese remember them easily. Some English trademarks with too many syllables are read difficultly and hard to be remembered if they are translated word for word, so we can adopt the transliteration of short syllable to simplify the syllables. For example: McDonald was not translated as “麦克 唐纳德”, but “麦当劳” in China; Rolls-Royce was not translated as “劳尔斯 - 罗伊斯” by using the pure transliteration, it is not better than the “劳斯莱斯” in China, the latter is more easy to be read and remembered. 
3) Pure transliteration. The pure transliteration translates trademarks word for word as similar Chinese pronunciation according to English pronunciation. Mainly it is applied to the proper noun when corresponding Chinese expression can not be found ${ }^{[3]}$.

a) Trademark named place. We analyze it through the following examples: the trademark of PONTIAC comes from a name of place which lies in the American Michigan; the Santana car, San Tana is the name of a valley which lies in American California.

b) Trademark named person. Some trademarks are the full name of people, such as: Walt Disney Film Co. was named according to Walt Disney which was the founder's name; Pierre Cardin fashionable dress was denominated according to the Pierre Cardin which was the producer's name. Some trademarks are composed of surname, such as: Hoover vacuum cleaner comes from the surname of William Henry Hoover. Some trademarks are made up of "person's name plus ' $s$ ", such as: Pond' s cosmetics is in honor of the Theron T. Pond who was the pharmaceutist in New York. Some trademarks are consisted of a name of a famous person or mythic person, such as: PICASSO comes from the name of famous artist PICASSO in the European middle century of Renaissance period; Milo chocolate comes from the name of Milo who was the famous athletes in ancient Greece.

\section{B. Free Translation}

In the means of the free translation, trademarks are translated as the same Chinese meaning or similar Chinese meaning according to the original meaning. The free translation can express better the original wish of the person who decided to adopt this trademark, some trademarks which have elegant implied meaning or magnificent words can adopt the free translation. The free translation can be divided into as follows: selective free translation, increasing or decreasing free translation and pure free translation [4].

1) Selective free translation. Some trademarks can not express the entire connotation if the trademarks are translated directly according to the direct meaning of the words. Or the direct meaning of the words is too complex to be expressed completely with concise words. So we had better choose the most representative meaning of the trademark. Such as: Play Boy dress, Play Boy can be translated as Chinese “娱乐男孩”, “玩耍男孩”, “花花公子” and so on, the “花花公子” has been chosen as the trademark at last.

2) Increasing or decreasing free translation. Through the increasing or decreasing free translation, the meaning contained is increased or decreased to be more appropriate for the consumption. Such as Transfer, the original meaning is Chinese “变换”, “变形”, the translator has increased the “金 刚” according to the potential psychology of Chinese consumers. The Chinese "金刚” exists in the Chinese national culture uniquely and is the name of Buddhist guard who holds the King Kong bar, so in their heart the King Kong is mighty, brave, competent and invincible. The King Kong is the children's idols and parents often educate their children to be brave and strong. So the toys are named “变形金刚” in China finally, and this trademark are popular very much with the Chinese children. This kind of translation is the increasing free translation. The Marlboro cigarette is the initials' abbreviation of Man Always Remembers Love Because of Romantic Only

(acronym), but there is not the same rhetoric in China, so it is translated as Chinese “万宝路” by decreasing the connotation.

3) Pure free translation. Some trademarks may be adopted the method of pure free translation, because they have the brilliant and elegant meaning both in the West and the East. Such as: the Nestle food was named by the Nestle who was the name of the founder. It refers to the feeling of "comfortless" and "warmness", in addition the Nestle and the nest (Chinese 雀巢） are near-synonyms, so the trademark was translated as “雀巢” in China. This name reflects infinite mother love and large role in daily life to some extent ${ }^{[5]}$.

\section{Combination of Transliteration and Free Translation}

Some trademarks are made up of fabrication words and thus contain more cultural connotation, so the combination of transliteration and free translation should be adopted. In other words, we should choose flexibly the transliteration or free translation to translate part or entire trademark and combine the transliteration or free translation to form an appropriate trademark. The method of translation is more complex than the other methods. Besides the fabrication words, some proper and common nouns can be translated through this kind of translation method as well.

1) Associatiing the mark with similar pronunciation. The association of similar pronunciation demands the name of trademark translation is similar to the original pronunciation, some beautiful Chinese names containing the characteristics of products can be associated with. Such as: the American Johnson \& Johnson Co. was founded in 1887 which always specializes in the products of medicine and health protection by the following three brothers: Robert Wood Johnson, James Wood Johnson and Edward Mead Johnson. If we translated it directly as Chinese “约翰逊”, there would not have been any special. But if we associate with similar pronunciation to translate it as Chinese “强生”, it will be better and easy to be associated with the strong vitality and health protection of the company in China. American Hewlett-Packard Co. which is a large producer of electronic equipment and miniature computer in the world, his trademark combines the two founders' name: W . Hewlett and D . Packard, the abbreviation of the trademark is "HP", and it was translated as “惠普” which make Chinese produce the association with Chinese “惠益普及”.

2) Similar pronunciation and implied meaning. This kind of translation refers to the translation is the same or similar to the pronunciation and meaning of the original trademark. It pays more attention to the "implied meaning", and the "pronunciation" only plays the bridge's role in the original trademark. The similar pronunciation and implied meaning can be classified into the following two aspects: half similar pronunciation and meaning, entire similar pronunciation and meaning ${ }^{[6]}$. 
3) Half similar pronunciation and meaning. Half similar pronunciation and meaning demands the partial pronunciation and partial meaning of the trademark, it includes two forms: the front pronunciation and the behind meaning, the front meaning and the behind pronunciation. The former like: the Disneyland casino, “Disney" can be transliterated as “迪斯尼” in China, “land” means Chinese “乐园”, that is Chinese “迪斯 尼乐园”.

4) Entire similar pronunciation and meaning. Entire similar pronunciation and meaning demands all the pronunciation and the meaning of the translation are similar to the original trademark. Such as: the American Pampers Co.(P $\& \mathrm{G})$ which is the producer of diaper, its former meaning of the trademark is Chinese “娇养”, that is the meticulous care for the baby, but the Chinese translation's “帮宝适” containing the meaning of helping the baby feel more comfortable and better and expresses the original meaning of the trademark. The Nike is the American merchandise of sport series, and its original meaning of the trademark is invincible which comes from the name of Nike in the Greek fairy tale. The translator has imitated the syllables and translated it as “耐 克” in China which contains the meaning of strong and victory.

5) Method of quotation. Many trademarks are proper nouns or signals of concoctive words, according to the pronunciation of the original trademark, which involve the 5000 years of Chinese history through proper translation and create the new trademark which has deep meaning and Chinese characteristics. For example: BMW car, the trademark of BMW comes from the initials' abbreviation of Bayerishe Motoren Werke which is a car producer in Bavaria, German. The translator has translated it as Chinese “宝马” according to a ancient poetry written by Xin Qiji in the Chinese Song Dynasty. It will make the Chinese consumers associate it with the swift horse which can travel very fast; the characteristics of the car and the swift horse are connected ${ }^{[7]}$.

6) Similar pronunciation's transfer by meaning. This kind of translation considers both the pronunciation and the meaning, generally the original trademarks are the meaningful words or phrases, but in accordance with the Chinese cultural habits, the meaning is transferred. The meaning differs from the original meaning; it should be creative and limited to a certain extent. For example: Sprite beverage, this word means "fairy", "genius" in English. In the drama of Shakespeare, the "fairy" is very lovely. Before the eve of the Halloween in the Western, the children will disguise themselves as all kinds of "fairy", "genius" and ask for the candy from door to door, but the fairy and genius are evil in Chinese heart. So direct translation is not appropriate, so it has been transferred to Chinese “雪碧”. The former “雪” means fresh and clean in China, the latter “碧” refers to exquisiteness. This similar pronunciation's transfer by meaning is much better than direct translation. The Dove is a trademark of daily products including chocolate, and it means "pigeon" in English, this translation is not relevant with the products. As a trademark of chocolate, it has been translated as “德芙” in China which accompanied by the advertisement: Good milk, delicate feeling, sweet scent and pure aftertaste, Chinese may make a good impression on it. With reference to daily products, it has been translated as “多芬” in China containing the meaning of moisture and fragrance. Both above translation are much better than the "pigeon".

\section{Other Strategies of Translation}

If the transliteration, the free translation, the combination of transliteration and free translation all can not translate vividly the name of the trademark's name, features or connotation, we are able to develop a new method creatively. Now this article generalizes the following several strategies:

1) Translation by outer design and meaning. The trademark often is composed of two parts: the name and the design. So called translation by outer design and meaning refers to the translation according to the meaning of the trademark's design. Such as: the original trademark of Wrigley's chewing gum is the name of producer, the translator considered the green arrowhead design on the outer packing and named it as Chinese “绿箭”, this translation is not only vivid and easy to be remembered, but also attractive to the consumers. Referring to the Remi Martin, whichever the transliteration or the free translation can not express effectively the characteristics and flavor of the merchandise, but the design of a horse in the packing with a human head made a deep impression on Chinese, so the “人头马” is adopted in China. ${ }^{[8]}$.

2) Unusual translation. This kind of translation differs from the traditional strategies of translation and pays attention to the selling point. It may be bizarre and justify itself without rules, so we name it as unusual translation. For example: famous Danish Kieldsens cookie, before entering into Chinese market, it was translated as Chinese “蓝罐” which showed the color and shape of its outer packing but not the simple transliteration only. This unusual translation aims at the strategies of sales promotion for the neutral middle class in the Chinese market and fully avails the outstanding blue canned packing to make the sales promotion. American "Duracell" is composed of the "durable cell", it implicates the full electric quantity of their products and durability. But the Chinese has translated it as “金霸王” in order to make better sales promotion by means of the image of strong Conqueror of Xiang $\mathrm{Yu}$ in Chinese history, the originality is unique and proper.

3) Transferring transliteration. The transferring transliteration refers to this kind of translation that uses the same original trademark without any change; usually the method is applied to the abbreviated trademark. When entering into the market, it can be translated directly the words, alphabets, figure and so on of the trademark the same as the original. Such as: the abbreviation of Minnesota Mining and Manufacturing Company is " $3 \mathrm{M}$ ", the transferring transliteration is " $3 \mathrm{M}$ " in China. The abbreviation of Nippon Electric Company is "NEC", the transferring transliteration is "NEC" too. International Business Machine Corp. has been transliterated by direct transferring as "IBM". These following trademarks are the examples of transferring transliteration as well: M\&M food, LG electric appliance, SK-II, C.D., UP2U and so on. 


\section{ATTENTION ITEMS OF TRADEMARK TRANSLATION}

\section{A. Simplicity}

With reference to the transliteration of trademark, only the simple and straight trademark can attract the consumers and make deep impressions on them. Therefore the Chinese trademark after being transliterated had better be less four Chinese words. If the original English trademarks surpass four syllables, some pronunciation with little or no stress should be passed over. Maybe some English consecutive consonantal sounds' syllables are less and easy to read in English, but if we translate each pronunciation and read in Chinese will be long and hard to be read, so we had better delete them accordingly. Such as: American Budweiser beer had been translated as “百 德威斯” before, of course the prevailing “百威” is more simple and better than the former translation in China.

\section{B. Appropriate Words.}

With reference to the free translation of trademark, the appropriate words should be selected. Because the free translation of trademark adopts meaningful words or phrases commonly and contains itself the wish of the dealers, some English trademark can give prominence to the roles or characteristics of the products. It is difficult for translator to fully express the meaning and consider enough cultural difference between the China and the West. So we had better refine the words to avoid the unnecessary cultural conflicts. Such as: OPIUM perfume, Yves saint Laurent was the designer of this trademark who came to China in 1977, his inspiration was aroused by the shape of Chinese snuff bottle, the meaning of the trademark is opium. Certainly this kind of trademark is not appropriate to the Chinese, Chinese may call to remembrance of the humiliating Opium War, and the intense national self proper pride made the perfume seriously deprecated by Chinese consumers, and was prohibited from selling because of acting against Chinese Trademark Law in the end. So the translator should pay attention to refine the words and select the appropriate words [9] in order not to offend the people's culture in China.

\section{Materialization of Products Features}

The trademark itself is a concise and powerful advertisement. The combination of transliteration and free translation's trademark make a deeper and direct impression on the people than the trademark through the method of transliteration and free translation. Thus aiming at the combination of transliteration and free translation, the translator should reflect well the characteristics of the products. Such as: Colgate toothpaste, from the name of the trademark which is the founder's name, it is difficult to see the characteristics of the products. But the combination of transliteration and free translation's trademark translation in China is “高露洁”, the “洁” not only states the category of the merchandise and stresses the characteristics of the product.

\section{Relevance.}

Most of the other strategies of translation are not limited to the traditional routines of translation and should be creative more bravely. Although without any rule which can be observed, this kind of translation strategies are close relevant to the products and can be found the relevant parts of the translation in each part of the products. For example: a kind of American food "Quaker", the original meaning is "shaking", the translator has translated it as “老人” in China according to the head portrait of Christian elder in the outer packing. Craven cigarette, the original meaning of the trademark is “cowardly person", the Chinese translation is “黑猫” which comes from the design of the trademark (there is a black cat in the packing). So although the trademark is bizarre, it can not deviate from the products.

\section{CONCLUSION}

The trademark translation is very important in reality, only when we cogently apply those methods and techniques which respect the national culture and custom and try to figure out the psychology of the consumers, the trademark translation can receive good effects and promote the consumption. If one good merchandise with one interesting or pleasant name, it will be popular with the consumers more. Good trademark translation can reflect the perfect combination of translation's techniques and aesthetic art. The English trademark's translation should be correct and appropriate without missing the art and commerce of the original language, and then accomplish the aim of wide propaganda and good sales promotion. In the meantime the trademark translation should be meaningful, can widen the study space of linguistics, and promote the combination of linguistic theory study and practical application.

\section{ACKNOWLEDGMENT}

I would like to give my heartfelt thanks to many people for their help in my academic studies over the past years.

My deepest gratitude to my family, thanks for their kindness, patience, encouragement. Thanks to my school that has give me this delicious opportunity. And thanks to my dear friends who have given their great help to me in my research.

\section{REFERENCES}

[1] ZhuE. Translation Theory and Methods of Trademark words[J]. Journal of Zhao Tong Higher Teachers Institute, 2004, (12).

[2] YuFulin. Commercial English Translation: From English to Chinese[M]. BeiJing: Publishing House of China Business Affairs, 2003.

[3] LvHua. Culture Features and Translation Strategies of Trademark[J]. Journal of HuaiY in Teachers College, 2005,(2).

[4] The same as [3].

[5] YouYuxiang. Culture's Flexible Application of Trademark Translation[J]. Journal of AnHui Teacher's University, 2005, (33).

[6] The same as [1].

[7] ZhaoGuihua. Theory and Techniques of Translation[M]. Haerbin: Press of Haerbin Industry University, 2002,(6).

[8] LiQifeng. English Trademark Translation[J]. Journal of ChongQing Universary, 2007, (6).

[9] The same as [7]. 